BMJ Open

Diabetes

Research

\& Care

\title{
Effect of motivational interviewing on gestational weight gain and fetal growth in pregnant women with type 2 diabetes
}

\author{
Björg Ásbjörnsdóttir (1) ,1,2 Marianne Vestgaard, ${ }^{1,2}$ Lene Ringholm, ,1,3 \\ Lise Lotte Torvin Andersen, ${ }^{4}$ Dorte Møller Jensen, ${ }^{4,5}$ Peter Damm, ${ }^{1,2}$ \\ Elisabeth R Mathiesen ${ }^{1,2}$
}

To cite: Ásbjörnsdóttir B, Vestgaard M, Ringholm L, et al. Effect of motivational interviewing on gestational weight gain and fetal growth in pregnant women with type 2 diabetes. BMJ Open Diab Res Care 2019;7:e000733. doi:10.1136/ bmjdrc-2019-000733

Received 3 July 2019 Revised 25 September 2019 Accepted 1 October 2019

Check for updates

(C) Author(s) (or their employer(s)) 2019. Re-use permitted under CC BY-NC. No commercial re-use. See rights and permissions. Published by BMJ.

${ }^{1}$ Center for Pregnant Women with Diabetes, Departments of Endocrinology and Obstetrics, Rigshospitalet, Copenhagen $\emptyset$, Denmark

${ }^{2}$ The Institute of Clinical Medicine, Faculty of Health and Medical Sciences, University of Copenhagen, Copenhagen, Denmark

${ }^{3}$ Steno Diabetes Center Copenhagen, Gentofte, Denmark

${ }^{4}$ Department of Gynecology and Obstetrics, Odense University Hospital, Odense, Denmark ${ }^{5}$ Steno Diabetes Center Odense, Odense, Denmark

Correspondence to Dr Björg Ásbjörnsdóttir; bjoerg.asbjoernsdottir.01@ regionh.dk

\section{ABSTRACT}

Objective To study how lifestyle coaching with motivational interviewing to improve adherence to healthy eating affects gestational weight gain and fetal growth in pregnant women with type 2 diabetes in a real-world setting.

Research design and methods A cohort study including a prospective intervention cohort of consecutive, singleton pregnant, Danish-speaking women with type 2 diabetes included between August 2015 and February 2018 and a historical reference cohort included between February 2013 and August 2015. The intervention consisted of a motivational interviewing to improve adherence to healthy eating in addition to routine care. The reference cohort received routine care only. The main outcomes were gestational weight gain and large for gestational age (LGA) infants.

Results Ninety-seven women were included in the intervention cohort and 92 in the reference cohort. Prepregnancy body mass index $\left(32.8 \pm 6.9 \mathrm{~kg} / \mathrm{m}^{2}\right.$ vs $32.4 \pm 7.4$ $\left.\mathrm{kg} / \mathrm{m}^{2}, \mathrm{p}=0.70\right)$, gestational weight gain $(9.2 \pm 5.8 \mathrm{~kg}$ vs $10.2 \pm 5.8 \mathrm{~kg}, \mathrm{p}=0.25), \mathrm{HbA} 1 \mathrm{c}$ in early pregnancy $(6.7 \% \pm 1.1 \%$ vs $6.5 \% \pm 1.3 \%(50 \pm 12 \mathrm{mmol} / \mathrm{mol}$ vs $48 \pm 14$ $\mathrm{mmol} / \mathrm{mol}), \mathrm{p}=0.32)$ and late pregnancy $(5.9 \% \pm 0.5 \%$ vs $6.0 \% \pm 0.6 \%(41 \pm 6 \mathrm{mmol} / \mathrm{mol}$ vs $42 \pm 7 \mathrm{mmol} / \mathrm{mol})$, $\mathrm{p}=0.34$ ) were comparable in the two cohorts. LGA infants occurred in $20 \%$ vs $31 \%, p=0.07$, respectively, and after adjustment for maternal characteristics $14 \%$ vs $27 \%$ delivered LGA infants $(p=0.04)$. Birth weight $z$-score was $0.24 \pm 1.36$ vs $0.61 \pm 1.38, p=0.06$.

Conclusions Motivational interviewing to improve adherence to healthy eating in addition to routine care in pregnant women with type 2 diabetes tended to reduce fetal overgrowth without major effect on gestational weight gain. Further studies investigating the cost-benefit of enhancing motivation are needed.

Trial registration number NCT02883127.

\section{INTRODUCTION}

The prevalence of type 2 diabetes in pregnancy is increasing, ${ }^{1}$ mainly due to decreased age of onset of type 2 diabetes. ${ }^{2}$

Fetal overgrowth is a major complication in women with type 2 diabetes and the prevalence of large for gestational age (LGA) infants is $23 \%-35 \% .^{3-5}$ Fetal overgrowth is

\section{Significance of this study}

What is already known about this subject?

- Poor maternal glycemic control and excessive gestational weight gain contribute to fetal overgrowth that is prevalent in pregnant women with type 2 diabetes.

- Motivational interviewing is effective in promoting adherence to diet programs and reducing body weight in non-pregnant patients with type 2 diabetes.

What are the new findings?

- Motivational interviewing to improve adherence to healthy eating in pregnant women with type 2 diabetes tended to reduce fetal overgrowth without major effect on gestational weight gain.

How might these results change the focus of research or clinical practice?

- Focus on motivation in clinical practice may improve pregnancy outcome in pregnant women with type 2 diabetes.

- Further studies investigating the cost-benefit of enhancing motivation in pregnant women with diabetes are needed.

associated with both maternal and neonatal complications, for example, shoulder dystocia, cesarean section and neonatal hypoglycemia $^{67}$ and long-term offspring risk of obesity and diabetes. ${ }^{8}$

Excessive gestational weight gain contributes to fetal overgrowth in healthy women ${ }^{910}$ and in women with diabetes independent of glycemic control and pre-pregnancy body mass index (BMI) ${ }^{511} 12$ However, obtaining appropriate gestational weight gain is challenging, especially in obese women,${ }^{13}$ leading to a high prevalence of excessive gestational weight gain in women with type 2 diabetes. ${ }^{513-15}$ Lifestyle intervention including diet, exercise or both combined during pregnancy in healthy women reduces the risk of excessive gestational weight gain on average by $20 \%{ }^{16}$ 
Motivational interviewing that focuses on enhancing the women's own motivation for lifestyle changes ${ }^{17}$ is effective in promoting adherence to diet and exercise programs ${ }^{18}$ and reducing body weight in non-pregnant patients with type 2 diabetes. ${ }^{19}$ During pregnancy, the Vitamin D and Lifestyle Intervention for GDM Prevention (DALI) study used motivational interviewing as an intervention in overweight and obese pregnant women. ${ }^{20}$ The intervention that included both diet and physical activity reduced gestational weight gain by $2.3 \mathrm{~kg}$ compared with the control group.

Lifestyle intervention studies enhancing motivation in pregnant women with type 2 diabetes are lacking.

The aim of the present study was to investigate how lifestyle coaching with motivational interviewing to improve adherence to healthy eating affects gestational weight gain and fetal growth in pregnant women with type 2 diabetes in a real-world setting.

\section{RESEARCH DESIGN AND METHODS}

\section{Study design}

A cohort study consisting of a prospective intervention cohort and a historical reference cohort in a real-world setting. The intervention consisted of a motivational interviewing to improve adherence to healthy eating in addition to routine care and was offered to all pregnant women with type 2 diabetes. The reference cohort received routine care only. The goals for glycemic control and gestational weight gain were the same in the two cohorts as was the routine obstetrical control and management. The focus of the motivational interviewing was to encourage the women to follow the recommended diabetes $\operatorname{diet}^{21}$ and to comply to local gestational weight gain recommendations. ${ }^{22}$ Gestational weight gain $(\mathrm{kg})$ and LGA infants (birth weight $>90$ th percentile) were the main outcomes.

\section{Study population}

All consecutive women with type 2 diabetes from a geographically well-defined region of approximately 4 million inhabitants were invited to participate from August 2015 to February 2018. The inclusion criteria were: singleton pregnancy before 20 weeks in women aged $\geq 18$ years. All women were followed at either Center for Pregnant Women with Diabetes, Rigshospitalet or Department of Obstetrics and Endocrinology, Odense University Hospital. The women were registered as having type 2 diabetes, if the diagnosis was present at referral. Women diagnosed with type 2 diabetes in early pregnancy with $\mathrm{HbAlc} \geq 6.5 \%$ ( $48 \mathrm{mmol} / \mathrm{mol})$ were also included (the intervention cohort: $\mathrm{n}=4$ and the reference cohort: $n=3$ ). Exclusion criteria were very few: previous bariatric surgery $(n=3)$ and for ethical reasons, insufficient Danish language skills $(n=40)$.

The reference cohort consisted of all pregnant women with type 2 diabetes treated at the centers in the period February 2013 to August 2015 and matched the same inclusion and exclusion criteria as the intervention cohort. If a woman had more than one pregnancy in the study period, the pregnancy in which she underwent intervention was the pregnancy included $(n=9)$. Data for the reference cohort were registered prospectively but collected retrospectively.

\section{The lifestyle intervention with motivational interviewing}

All women received individual one-to-one sessions with a lifestyle coach at each pregnancy visit at the centers, preferably every 2 weeks. The lifestyle coaching was based on principles of patient empowerment and cognitive behavioral techniques, inspired by motivational interviewing. ${ }^{17}$ An individual action plan for improving dietary behavior was made during the first session and evaluated and tailored in subsequent sessions. At each visit the following dietary objectives were presented for the patient, of which one was to be achieved or maintained until the next session: (1) watch portion size-focus on the amount of carbohydrates in each meal; (2) eat mainly carbohydrates of low glycemic index (for example, more vegetables or whole grain products); (3) reduce the intake of carbohydrate of high glycemic index (for example, less or no takeaway food, less or no cakes, candy, snacks, chips, ice cream, sugary beverage). Furthermore, the women were motivated to watch daily weight changes.

The lifestyle coaches were midwives, who had received special training in the motivational interviewing with focus on lifestyle changes as a part of the DALI study. ${ }^{20}$ During the DALI study, the midwives had regular assessment of their skills in the use of the motivational interviewing and had years of practical experience. The first session of the motivational interviewing lasted $45 \mathrm{~min}$. To minimize the time consumption for the patients and the caregivers, the sessions of motivational interviewing were thereafter sought combined with routine diabetes care within the time frame of one appointment, if possible. Women living a long distance from the clinic could convert a minor part of the one-to-one contacts to telephone calls with the lifestyle coaches.

Women in the intervention cohort were judged to be compliant to the intervention, if attending at least $80 \%$ of the visits.

\section{The routine diabetes care for both cohorts}

At the first pregnancy visit, the women received a oneto-one consultation with a nurse, a registered dietitian and a diabetologist. Thereafter, the women were seen by a diabetes caregiver preferably every 2 weeks throughout pregnancy.

The women received information from a dietitian about the recommended diabetes diet ${ }^{21}$ and education in carbohydrate exchange including an introduction to a local smartphone application with pictures and information on the carbohydrate amounts to aid learning. The goals were: (1) adequate nutrient intake to support a healthy pregnancy; (2) carbohydrates mainly deriving from low glycemic index sources; and (3) a total daily 
energy intake of approximately $1673 \mathrm{kcal}(7000 \mathrm{~kJ})$ including $175 \mathrm{~g}$ carbohydrates in total $(43 \mathrm{E} \%)$ with approximately $150 \mathrm{~g}$ deriving from the major carbohydrate sources (bread, potatoes, rice, pasta, fruits, and dairy products).

The women were encouraged to be physically active for at least $30 \mathrm{~min} /$ day if this was not medically contraindicated.

The goals for gestational weight gain followed the Copenhagen guidelines ${ }^{22}$ for pregnant women with diabetes according to pre-pregnancy BMI, that is, prepregnancy $\mathrm{BMI}<25 \mathrm{~kg} / \mathrm{m}^{2}$ : aiming for $100 \mathrm{~g} /$ week in the first half of pregnancy and thereafter $400 \mathrm{~g}$ /week with a total weight gain of $10-15 \mathrm{~kg}$. BMI $25-29.9 \mathrm{~kg} / \mathrm{m}^{2}$ : aiming for $100 \mathrm{~g}$ /week in the first half of pregnancy and thereafter $300 \mathrm{~g} /$ week, with a total weight gain of $5-8 \mathrm{~kg}$. $\mathrm{BMI} \geq 30 \mathrm{~kg} / \mathrm{m}^{2}$ : aiming for $0 \mathrm{~g} /$ week in the first half of pregnancy and thereafter $200 \mathrm{~g}$ /week, with a total weight gain of $0-5 \mathrm{~kg}$.

Self-monitored plasma glucose measurements were recommended seven times daily, aiming for preprandial plasma glucose values between 4 and $6 \mathrm{mmol} / \mathrm{L}$ and 90 min postprandial values between 4 and $8 \mathrm{mmol} / \mathrm{L}$. The aim for $\mathrm{HbAlc}$ was $<6.7 \%(50 \mathrm{mmol} / \mathrm{mol})$ in the first half of pregnancy and $<5.8 \%(40 \mathrm{mmol} / \mathrm{mol})$ in the second half of pregnancy.

Before pregnancy most women were treated with diet alone or in a combination with oral antidiabetic drugs and/or glucagon-like peptide-1 (GLP-1) analogs. At first pregnancy visit, the treatment with oral antidiabetic drugs and/or GLP-1 analogs was discontinued and not used during pregnancy. Therefore, insulin treatment was often initiated or tailored.

At each pregnancy visit, HbAlc and weight were measured, and a dipstick of sterile urine was screened for proteinuria and ketonuria. The daily insulin dose, the occurrence of mild hypoglycemia in the previous week and the median of each time point in the 7-point plasma glucose profile for 5 days were noted. These data were used for reinforcement of dietary advice and insulin dose adjustments.

\section{Procedure and data collection}

For both cohorts, maternal clinical data were collected at first pregnancy visit (early pregnancy visit) and at 35-37 weeks (late pregnancy visit). The women's self-reported weight and height before pregnancy, age at inclusion, duration of diabetes, gestational age at first visit, parity, ethnicity and smoking were noted.

The women were weighted on calibrated electronic scales without shoes or heavy clothes to the nearest 0.1 $\mathrm{kg}$. Gestational weight gain was defined as the difference between measured weights at the early and the late pregnancy visits. Within the three BMI classes (normal weight $\left(\mathrm{BMI}<25 \mathrm{~kg} / \mathrm{m}^{2}\right)$, overweight (BMI $\left.25-29.9 \mathrm{~kg} / \mathrm{m}^{2}\right)$ and obese $\left(\mathrm{BMI} \geq 30 \mathrm{~kg} / \mathrm{m}^{2}\right)$ ) gestational weight gain was categorized as follows based on the Institute of Medicine (IOM) 2009 recommendation $^{23}$ : insufficient $(<11.5,<7.0$ and $<5.0 \mathrm{~kg}$ for the BMI classes, respectively), appropriate $(11.5-16.0,7.0-11.5$ and $5.0-9.0 \mathrm{~kg})$ and excessive $(>16$, $>11.5$ and $>9 \mathrm{~kg}$ ).

HbA1c was analyzed immediately by a DCA 2000 analyzer by a latex immunoagglutination inhibition method (DCA 200; Bayer, Mishawaka, IN). Delta-HbA1c was defined as the difference between the HbAlc measurements at the early and the late pregnancy visits. The urine was analyzed by Siemens CLINITEK Status+Analyzer. The occurrence of ketonuria was noted if the concentration of ketone bodies was $\geq 4.0 \mathrm{mmol} / \mathrm{L}$. Diabetic retinopathy was assessed by retinal photoscreening and evaluated by an ophthalmologist. Diabetic nephropathy was defined as albumin-creatinine ratio $\geq 300 \mathrm{mg} / \mathrm{g}$ at the early pregnancy visit, based on two urine samples.

The data on maternal neck and ankle circumference and subcutaneous skinfolds were collected for the intervention cohort at the early and the late pregnancy visits. Neck circumference was obtained in a standing relaxed position in the midway of the neck, between mid-cervical spine and mid-anterior neck to within $1 \mathrm{~mm}$. Ankle circumference was measured $5 \mathrm{~cm}$ above the lateral malleolus at both ankles as a pragmatic estimate for the development of peripheral edema. Skinfold thickness at four areas (biceps, triceps, suprailiac and subscapular) was measured to the nearest millimeters with a Harpenden caliper $^{24}$ and given as a sum of skinfolds.

Furthermore, the women answered two questions in a questionnaire: 'How motivated are you for achieving good glycemic control during pregnancy' and 'How motivated are you for achieving appropriate gestational weight gain during pregnancy' on a Likert scale from 1 to 10 . A score $\geq 8$ on the Likert scale was considered as very motivated. The coaches were motivated for using the motivational interviewing but were not asked about their own motivation.

The following data on pregnancy outcome were retrieved from the medical records: gestational age at delivery, preterm delivery (before 37 completed weeks), cesarean section (elective and emergency), shoulder dystocia and the sex of the infant. Weight, length, and abdominal and head circumference of the infant were measured shortly after birth. Birth weight z-score was calculated by local growth curves adjusted for gestational age and infant sex. ${ }^{25}$ LGA and small for gestational age (SGA) were defined as birth weight $>90$ th and $<10$ th percentiles, respectively. As only half of the population was of Northern European origin, the prevalence of LGA and SGA infants was calculated by two different methods: first, by traditional Nordic growth curves ${ }^{25}$ adjusted for gestational age and infant sex; second, by using customized birth weight centiles (gestation-related optional weight, GROW ${ }^{26}$ ) adjusted for maternal height, weight, ethnic origin, parity, gestational age and infant sex. Perinatal mortality (offspring death after 20 gestational weeks or within the first 7 days of life), major congenital malformations (leading to death, causing a substantial future handicap or requiring surgery), neonatal hypoglycemia 
(defined as a plasma glucose value below $2.2 \mathrm{mmol} / \mathrm{L}$, measured within 4 hours of life ${ }^{27}$ ), jaundice (requiring phototherapy), and transient tachypnea (requiring continuous positive airway pressure for more than 60 $\min$ ) were noted. Perinatal morbidity was defined as the occurrence of at least one of the following complications: major congenital malformation, neonatal hypoglycemia, jaundice or transient tachypnea.

In addition, the infants in the intervention cohort had skinfold measurements of triceps, quadriceps, suprailiac and subscapular region measured to the nearest millimeter and performed with a Harpenden skinfold caliper $^{24}$ within 48 hours after birth.

\section{Statistical analyses}

Continuous data with normal distribution are reported as mean $\pm \mathrm{SD}$, continuous data with skewed distribution as median (IQR) and categorical data as number (\%). Comparison between the cohorts was performed by Student's t-test, Mann-Whitney U test, $\chi^{2}$ test or Fisher's exact test where appropriate. To control for the following covariates from the early pregnancy visit: nulliparity, smoking, pre-pregnancy BMI and HbAlc (\%), an analysis of covariance was used for comparison of gestational weight gain and birth weight z-score between the cohorts. Statistical analyses were performed with IBM SPSS Statistics V.22. Statistically significant differences were defined as a two-sided $\mathrm{p}<0.05$.

A priori, we performed a simple power analysis. Based on our previous study, ${ }^{5}$ we assumed a prevalence of LGA of $20 \%$ and $35 \%$ in the two cohorts and with a power of $80 \%, 135$ women were needed in each cohort to detect a significant difference.

\section{RESULTS}

In total, 116 and 103 women were included in the intervention and the reference cohort, respectively. Thirteen women in the intervention cohort had a miscarriage and six women withdrew their consent, while in the reference cohort 10 women had a miscarriage and one woman moved from the uptake area, resulting in $97(84 \%)$ and
$92(89 \%)$ women being included in the final analyses (figure 1A, B).

At the early pregnancy visit, the intervention cohort and the reference cohort were comparable regarding pre-pregnancy BMI, duration of diabetes, HbAlc and fraction on insulin treatment (tables 1 and 2).

The intervention cohort was very motivated to achieve good glycemic control and appropriate gestational weight gain where $85 \%$ and $84 \%$ scored $\geq 8$ on a Likert scale at the early pregnancy visit and $77 \%$ and $72 \%$ at the late pregnancy visit, respectively.

The total gestational weight gain was $9.2 \pm 5.8 \mathrm{~kg}$ in the intervention cohort vs $10.2 \pm 5.8 \mathrm{~kg}$ in the reference cohort, $\mathrm{p}=0.25$, corresponding to a weekly gestational weight gain of $0.26 \pm 0.16 \mathrm{~kg}$ vs $0.28 \pm 0.16 \mathrm{~kg}, \mathrm{p}=0.31$, respectively (table 2 ). The percentage of women with excessive gestational weight gain was $34.4 \%(32 / 93)$ in the intervention cohort and $45.4 \%(40 / 88)$ in the reference cohort $(p=0.13)$ (table 2$)$, corresponding to $24 \%$ fewer cases with excessive gestational weight gain in the intervention cohort compared with the reference cohort. After adjustment for nulliparity, smoking, pre-pregnancy BMI and HbAlc (\%) from the early pregnancy visit, the difference in gestational weight gain between the cohorts remained insignificant $(p=0.24)$. Few women lost weight during pregnancy in the two cohorts (table 2).

Within the intervention cohort the sum of maternal skinfold measurements and neck circumference was unchanged during pregnancy, while the ankle circumferences increased by $1.6 \mathrm{~cm}$ at each ankle, $\mathrm{p}<0.001$ (table 2).

During pregnancy, most women in both cohorts were treated with insulin, and at the late pregnancy visit the median daily insulin dose per kilogram body weight was $0.95(0.66-1.51) \mathrm{IU} / \mathrm{kg}$ in the intervention cohort compared with $0.74(0.40-1.28) \mathrm{IU} / \mathrm{kg}$ in the reference cohort $(\mathrm{p}=0.03) \quad($ table 2$)$.

HbAlc was comparable at the early pregnancy $(6.7 \% \pm 1.1 \%$ vs $6.5 \% \pm 1.3 \%(50 \pm 12 \mathrm{mmol} / \mathrm{mol}$ vs $48 \pm 14$ $\mathrm{mmol} / \mathrm{mol}), \mathrm{p}=0.32)$ and the late pregnancy $(5.9 \% \pm 0.5 \%$ vs $6.0 \% \pm 0.6 \%(41 \pm 6 \mathrm{mmol} / \mathrm{mol}$ vs $42 \pm 7 \mathrm{mmol} / \mathrm{mol})$,

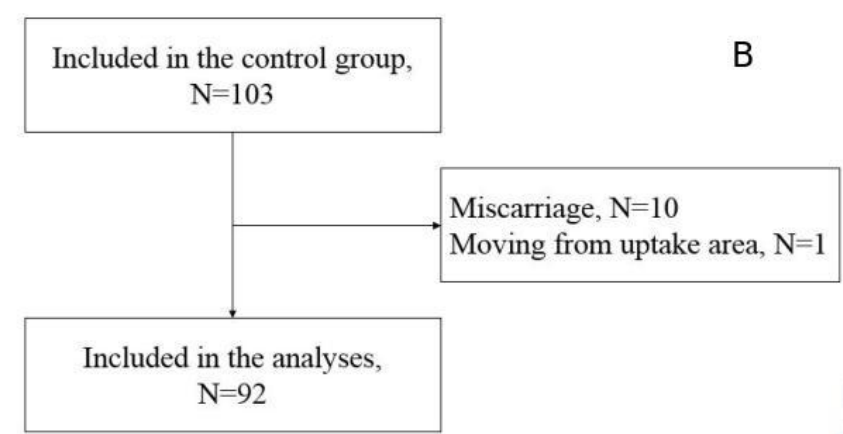

Included in the analyses, $\mathrm{N}=97$

Figure 1 (A) Flowchart for inclusion in the intervention cohort. (B) Flowchart for inclusion in the reference cohort. 
Table 1 Clinical characteristics among pregnant women with type 2 diabetes in the intervention cohort compared with the reference cohort at the early pregnancy visit

\begin{tabular}{|c|c|c|c|}
\hline & $\begin{array}{l}\text { Intervention } \\
\text { cohort }\end{array}$ & $\begin{array}{l}\text { Reference } \\
\text { cohort }\end{array}$ & $P$ value \\
\hline $\mathrm{n}$ & 97 & 92 & \\
\hline Age (years) & $34 \pm 5$ & $34 \pm 6$ & 0.52 \\
\hline $\begin{array}{l}\text { Duration of } \\
\text { diabetes (years) }\end{array}$ & $3(1-8)$ & $2.5(0.5-5)$ & 0.08 \\
\hline $\begin{array}{l}\text { Diabetes } \\
\text { retinopathy* }\end{array}$ & $10(12)$ & $3(5)$ & 0.16 \\
\hline $\begin{array}{l}\text { Diabetes } \\
\text { nephropathy }\end{array}$ & $1(1)$ & 0 & 1.00 \\
\hline $\begin{array}{l}\text { North European } \\
\text { origin }\end{array}$ & $56(58)$ & $44(48)$ & 0.17 \\
\hline Nullipara & $41(42)$ & $29(32)$ & 0.13 \\
\hline Smoker & $10(11)$ & $18(20)$ & 0.13 \\
\hline Height (cm) & $165.6 \pm 7.2$ & $163.9 \pm 7.6$ & 0.11 \\
\hline $\begin{array}{l}\text { Pre-pregnancy } \\
\text { BMI }\left(\mathrm{kg} / \mathrm{m}^{2}\right)\end{array}$ & $32.8 \pm 6.9$ & $32.4 \pm 7.4$ & 0.70 \\
\hline \multicolumn{4}{|l|}{ BMI classes } \\
\hline$\leq 24.9 \mathrm{~kg} / \mathrm{m}^{2}$ & $14(14)$ & 17 (18) & 0.75 \\
\hline $25.0-29.9 \mathrm{~kg} / \mathrm{m}^{2}$ & $21(22)$ & $19(21)$ & \\
\hline$\geq 30.0 \mathrm{~kg} / \mathrm{m}^{2}$ & $62(64)$ & $56(61)$ & \\
\hline
\end{tabular}

Data are given as mean $\pm \mathrm{SD}$, median (IQR) or $\mathrm{n}(\%)$. Data available in $85 \%-100 \%$ unless otherwise stated.

${ }^{*}$ Data available from $87 \%$ vs $64 \%$.

BMI, body mass index.

$\mathrm{p}=0.34$ ) visits. However, the decline in HbAlc during pregnancy was greater in the intervention cohort compared with the reference cohort $(-0.6(-1.3$ to -0.2$) \%$ vs -0.2 $(-1.0$ to 0.1$) \%(-7$ ( -14 to -2$) \mathrm{mmol} / \mathrm{mol}$ vs $-2(-11$ to 1) $\mathrm{mmol} / \mathrm{mol}$ ), $\mathrm{p}=0.01$ ) (table 2).

The prevalence of LGA infants was $20 \%$ vs $31 \%$, $\mathrm{p}=0.07$, in the intervention cohort compared with the reference cohort (table 3 ). The figures when using the customized GROW curves, taking maternal characteristics into account, were $14 \%$ vs $27 \%, \mathrm{p}=0.04$ (table 3 ). The intervention cohort delivered infants with a birth weight z-score of $0.24 \pm 1.36$ compared with $0.61 \pm 1.38$ in the reference cohort $(\mathrm{p}=0.06)$. After adjustment for nulliparity, smoking, pre-pregnancy BMI and HbAlc (\%) from the early pregnancy visit the difference in birth weight $\mathrm{z}$-score remained insignificant between the cohorts $(\mathrm{p}=0.11)$. The occurrence of perinatal mortality and morbidity was similar in the two cohorts (table 3 ).

When restricting the analyses to the $86 \%$ of the intervention cohort judged compliant to the intervention, similar gestational weight gain, occurrence of LGA infants and birth weight z-score were obtained as for the total cohort (data not shown).

Transient tachypnea of the newborn tended to be less common in the intervention cohort compared with the reference cohort $(10 \%$ vs $20 \%, \mathrm{p}=0.06)$, while major congenital malformation $(\mathrm{p}=0.68)$, neonatal hypoglycemia $(\mathrm{p}=0.86)$ and jaundice $(\mathrm{p}=0.38)$ were comparable between the cohorts (table 3 ).

When dividing the cohorts into women of North European origin and non-North European origin, comparable gestational weight gain was obtained in the intervention cohort $(9.2 \pm 6.0 \mathrm{~kg}$ vs $9.2 \pm 5.5 \mathrm{~kg}, \mathrm{p}=0.96)$ and in the reference cohort $(9.7 \pm 6.2$ vs $10.7 \pm 5.4, \mathrm{p}=0.42)$. The prevalence of LGA infants was $20 \%$ vs $20 \%, \mathrm{p}=0.99$, in the intervention cohort and $37 \%$ vs $26 \%, p=0.23$, in the reference cohort, respectively, with the birth weight z-score of $0.11 \pm 1.25$ vs $0.40 \pm 1.50, \mathrm{p}=0.32$, and $0.71 \pm 1.31$ vs 0.52 vs $1.44, \mathrm{p}=0.53$.

\section{CONCLUSIONS}

In this cohort study consisting of an intervention cohort and a historical reference cohort there was a trend towards a reduced prevalence of fetal overgrowth, when using motivational interviewing to improve adherence to healthy eating in addition to routine care. The average gestational weight gain was comparable between the cohorts.

To our knowledge, this is the first lifestyle intervention study performed in pregnant women with type 2 diabetes.

Although the women in the intervention cohort received additional help to improve motivation for healthier eating habits, it was still challenging for many of the women to achieve appropriate gestational weight gain. However, we found a non-significant reduction in excessive gestational weight gain of $24 \%$, which is comparable to the $23 \%$ reduction seen in healthy pregnant women exposed to dietary intervention ${ }^{16}$ and lower than the $41 \%-63 \%$ previously reported in the literature. ${ }^{513-15}$

Three randomized controlled trials (RCT) using lifestyle intervention in healthy, overweight and obese pregnant women without diabetes found a reduced gestational weight gain of $1.5-2.3 \mathrm{~kg}$ in the intervention groups compared with the control groups ${ }^{20} 2829$ while three studies showed no effect on the gestational weight gain. $^{30-32}$ The obtained non-significant reduction in gestational weight gain of $1.0 \mathrm{~kg}$ in our study is thus close to what is obtained in healthy, overweight and obese women exposed to a lifestyle intervention.

The mean gestational weight gain in the intervention cohort was $9.2 \mathrm{~kg}$, which is the same as the expected weight gain due to physiological changes in pregnancy, which has been estimated to $9.2 \mathrm{~kg}$ without taking the increase in maternal fat stores into account. ${ }^{33}$ The women in the intervention cohort had documented a stable sum of skinfolds throughout pregnancy but developed signs of peripheral edema in late pregnancy, indicating that edema formation without increase in maternal subcutaneous fat mass can explain some of the obtained weight gain.

Most of the published lifestyle studies chose a combination of diet and physical activity changes as the intervention, ${ }^{16}$ including the DALI study. ${ }^{20}$ In the DALI study, 
Table 2 Maternal glycemic control and weight changes during pregnancy among women with type 2 diabetes in the intervention cohort compared with the reference cohort

\begin{tabular}{|c|c|c|c|}
\hline & Intervention cohort & Reference cohort & $P$ value \\
\hline Gestational age at the early pregnancy visit (days) & $83 \pm 26$ & $76 \pm 23$ & 0.04 \\
\hline $\mathrm{HbA} 1 \mathrm{c}$ at the early pregnancy visit (\%) & $6.7 \pm 1.1$ & $6.5 \pm 1.3$ & 0.32 \\
\hline $\mathrm{HbA} 1 \mathrm{c}$ at the early pregnancy visit $(\mathrm{mmol} / \mathrm{mol})$ & $50 \pm 12$ & $48 \pm 14$ & \\
\hline $\mathrm{HbA} 1 \mathrm{c}$ at the late pregnancy visit (\%) & $5.9 \pm 0.5$ & $6.0 \pm 0.6$ & 0.34 \\
\hline $\mathrm{HbA} 1 \mathrm{c}$ at the late pregnancy visit $(\mathrm{mmol} / \mathrm{mol})$ & $41 \pm 6$ & $42 \pm 7$ & \\
\hline$\Delta \mathrm{HbA} 1 \mathrm{c}(\%)^{*}$ & $-0.6(-1.3$ to -0.2$)$ & $-0.2(-1.0$ to 0.1$)$ & 0.01 \\
\hline$\triangle \mathrm{HbA} 1 \mathrm{c}(\mathrm{mmol} / \mathrm{mol})$ & $-7(-14$ to -2$)$ & $-2(-11$ to 1$)$ & \\
\hline Women with ketonuria at the early pregnancy visit $(4-15.9 \mathrm{mmol} / \mathrm{L})$ & $2(2)$ & $5(6)$ & 0.25 \\
\hline Women with ketonuria at the late pregnancy visit $(4-15.9 \mathrm{mmol} / \mathrm{L})$ & $2(2)$ & $3(4)$ & 0.67 \\
\hline Weight at the early pregnancy visit $(\mathrm{kg})$ & $91.9 \pm 22.0$ & $89.6 \pm 23.5$ & 0.48 \\
\hline Weight at the late pregnancy visit $(\mathrm{kg})$ & $101.3 \pm 21.3$ & $100.3 \pm 23.8$ & 0.78 \\
\hline Total gestational weight gain $(\mathrm{kg})$ & $9.2 \pm 5.8$ & $10.2 \pm 5.8$ & 0.25 \\
\hline Total gestational weight gain/week (kg) & $0.26 \pm 0.16$ & $0.28 \pm 0.16$ & 0.31 \\
\hline \multicolumn{4}{|l|}{ Gestational weight gain according to IOM's recommendations } \\
\hline Insufficient & $29(31.2)$ & $24(27.3)$ & 0.31 \\
\hline Appropriate & $32(34.4)$ & $24(27.3)$ & \\
\hline Excessive & $32(34.4)$ & $40(45.4)$ & \\
\hline Women with weight loss during pregnancy & $5(5)$ & $4(5)$ & 1.00 \\
\hline \multicolumn{4}{|l|}{ Neck circumference $(\mathrm{cm})$} \\
\hline At the early pregnancy visit & $37.5 \pm 4$ & - & 0.24 \\
\hline At the late pregnancy visit & $37.7 \pm 4$ & - & \\
\hline \multicolumn{4}{|l|}{ Ankle circumference $(\mathrm{cm})$} \\
\hline At the early pregnancy visit & $24.1 \pm 3$ & - & $<0.001$ \\
\hline At the late pregnancy visit & $25.7 \pm 4$ & - & \\
\hline \multicolumn{4}{|l|}{ Sum of skinfolds $(\mathrm{cm}) \dagger$} \\
\hline At the early pregnancy visit $(\mathrm{cm})$ & $11.2 \pm 3.1$ & - & 0.29 \\
\hline At the late pregnancy visit & $11.5 \pm 3.0$ & - & \\
\hline Women on insulin treatment before the early pregnancy visit & $21(23)$ & $24(28)$ & 0.43 \\
\hline Women on insulin treatment at the late pregnancy visit & $89(96)$ & $77(89)$ & 0.07 \\
\hline Insulin dose at the late pregnancy visit (IU/kg) & $0.95(0.66-1.51)$ & $0.74(0.40-1.28)$ & 0.03 \\
\hline $\begin{array}{l}\text { Women with } \geq 1 \text { episode of hypoglycemia the previous week at the late } \\
\text { pregnancy visitf }\end{array}$ & $39(47)$ & $16(28)$ & 0.02 \\
\hline
\end{tabular}

Data are given as mean \pm SD, median (IQR) or $n(\%)$. Data available in $87 \%-100 \%$ unless otherwise stated.

${ }^{*} \Delta \mathrm{HbA} 1 \mathrm{c}$ was defined as the difference between measurements at the early and the late pregnancy visits.

†Sum of skinfold measurements of triceps, quadriceps, subscapular and suprailiac region.

łInsulin-treated women only, with data available from $93 \%$ vs $74 \%$, respectively.

IOM, Institute of Medicine.

a $2.3 \mathrm{~kg}$ lower gestational weight gain and reduced offspring adiposity measured by the sum of skinfolds was documented in the intervention group compared with the control group. ${ }^{20}{ }^{34}$ However, the compliance to the exercise part of the intervention has been documented low $^{283536}$ and a reduction in physical activity during pregnancy is reported. ${ }^{3536}$ Aiming for a successful compliance to lifestyle changes, it is probably important to limit the number of tasks to change, and we asked the women to focus only on one of the dietary goals at a time. Whether the effect on gestational weight gain and fetal growth might have been more pronounced if goals for physical activity were added to the dietary intervention needs further investigation.

The intervention was not associated with a lower need for insulin; contrary, the intervention cohort received a higher insulin dose and had more often hypoglycemia at the late pregnancy visit compared with the reference cohort. Insulin is a growth factor and both insulin and hypoglycemia stimulate appetite and this may have influenced the effect on the gestational weight gain. 
Table 3 Pregnancy outcomes among women with type 2 diabetes in the intervention cohort compared with the reference cohort

\begin{tabular}{|c|c|c|c|}
\hline & $\begin{array}{l}\text { Intervention cohort } \\
(\mathrm{n}=97)\end{array}$ & $\begin{array}{l}\text { Reference cohort } \\
(\mathrm{n}=92)\end{array}$ & $P$ value \\
\hline Gestational age at delivery (days) & $263(260-270)$ & $266(259-268)$ & 0.98 \\
\hline Preterm delivery ( $<37$ weeks) & $19(20)$ & $16(17)$ & 0.70 \\
\hline Cesarean section & $44(45)$ & $46(51)$ & 0.48 \\
\hline Shoulder dystocia & $1(1)$ & $1(1)$ & 1.00 \\
\hline Female offspring & $41(42)$ & $48(52)$ & 0.17 \\
\hline Birth weight $(\mathrm{g})$ & $3167 \pm 659$ & $3324 \pm 636$ & 0.10 \\
\hline Birth length $(\mathrm{cm})$ & $50.4 \pm 3$ & $50.5 \pm 2$ & 0.85 \\
\hline Abdominal circumference $(\mathrm{cm})$ & $32.2 \pm 2$ & $32.8 \pm 2$ & 0.15 \\
\hline Head circumference $(\mathrm{cm})$ & $34.4 \pm 2$ & $34.4 \pm 2$ & 0.90 \\
\hline Sum of skinfolds $(\mathrm{cm})^{\star}$ & $2.21(1.88-2.75)$ & - & \\
\hline Birth weight z-score & $0.24 \pm 1.36$ & $0.61 \pm 1.38$ & 0.06 \\
\hline Large for gestational age (Nordic curves) $\dagger$ & $19(20)$ & $28(31)$ & 0.07 \\
\hline Small for gestational age (Nordic curves) $\dagger$ & $11(11)$ & $5(6)$ & 0.16 \\
\hline Large for gestational age (GROW curves) $\ddagger$ & $14(14)$ & $24(27)$ & 0.04 \\
\hline Small for gestational age (GROW curves)‡ & $14(14)$ & $7(8)$ & 0.15 \\
\hline Perinatal mortality & $1(1)$ & $1(1)$ & 1.00 \\
\hline Perinatal morbidity§ & $34(35)$ & $37(42)$ & 0.39 \\
\hline Major congenital malformations & $2(2)$ & $3(3)$ & 0.68 \\
\hline Neonatal hypoglycemia (<2.2 mmol/L) & $15(16)$ & $14(17)$ & 0.86 \\
\hline Jaundice & $15(16)$ & $10(11)$ & 0.38 \\
\hline Transient tachypnea & $10(10)$ & $18(20)$ & 0.06 \\
\hline
\end{tabular}

Data are given as median (IQR), n (\%) or mean \pm SD. Only live births included and one woman in the reference cohort gave birth at another hospital and detailed data are missing. Data available from $87 \%$ to $100 \%$ if not otherwise stated.

${ }^{\star}$ Sum of skinfold measurements of triceps, quadriceps, subscapular and suprailiac region, data on $58 \%$.

$\dagger>90$ th and $<10$ th percentiles using Nordic growth curves adjusted for gestational age and infant sex.

$\ddagger>90$ th and $<10$ th percentiles using customized birth weight centiles adjusted for maternal height, weight, ethnic origin and parity in addition to gestational age and infant sex (gestation-related optional weight, GROW).

§Perinatal morbidity was defined as the occurrence of at least one of the following complications: major congenital malformation, neonatal hypoglycemia, jaundice and transient tachypnea.

The birth weight z-score is based on growth curves for a Nordic population. ${ }^{25}$ Half of the women in this study were of other ethnic origin and therefore data on infant overgrowth are given both using the Nordic growth curves adjusted for gestational age and infant sex and the customized growth curves by GROW ${ }^{26}$ where maternal height, weight, ethnic origin, parity, and gestational age and infant sex are taken into account, too. It is reassuring that the prevalence of LGA infants is similar regardless of the method used. The observed reduction in average birth weight z-score and the prevalence of LGA infants in this study is clinically meaningful. It did not convert to significantly reduced perinatal morbidity, but whether this reduction in fetal overgrowth will affect the longterm risk of obesity and type 2 diabetes later in life remains speculative. The occurrence of SGA infants in this study is close to the $10 \%$ expected in the background population.
Whether the more appropriate fetal growth in the intervention cohort could be explained mainly by motivational interviewing leading to healthier eating habits or whether the more intensive insulin therapy in the intervention cohort played the major role cannot be determined from our results. However, it is known that maternal lipids and protein consumption as well as micronutrients affect fetal growth. ${ }^{37}$ It is possible that the women in the intervention cohort established overall better eating habits compared with the reference cohort, resulting in more appropriate fetal growth, not mediated by restricted gestational weight gain. Possible differences in nulliparity, smoking, pre-pregnancy BMI, and glycemic control between the groups at the early pregnancy visit have been taken into account by performing statistical analyses with and without these covariates.

The clinical benefits of avoiding transient tachypnea include better possibilities for skin-to-skin contact, maternal-child bonding and successful breast feeding. Both 
fetal overgrowth and transient tachypnea of the newborn tended to be less common in the intervention cohort. Whether this is related to less fetal hyperinsulinemia needs to be clarified in further studies.

It is a strength that this cohort study included consecutive women with type 2 diabetes from a large population with very few exclusion criteria and was conducted in a real-world setting. Therefore, we are most likely studying an unselected population of pregnant women with type 2 diabetes, also including the vulnerable women from more deprived areas. This makes the study results applicable to the relevant population. In an RCT, vulnerable women would often not participate even though they probably were the ones needing motivation for lifestyle changes the most. Another potential problem with an RCT including lifestyle interventions is the Hawthorne effect, that is, the women accepting inclusion are often very motivated, which results in improved lifestyle in the control group, too. This is not the case in our study where a historical cohort that was totally unaware of the intervention was included. The study was planned with a minimal excess use of one-to-one contact with a caregiver and the women followed their routine visits, enabling the women to participate regardless of parity, economy or occupation. Furthermore, this enables the motivational interviewing technique to be implemented as routine care. However, resources of an extra diabetes caregiver of approximately $240 \mathrm{~min}$ per women were applied.

By including measurements of maternal skinfolds and ankle circumferences, we obtained a rough estimate of changes in maternal subcutaneous fat and fluid retention.

The limitation of ending up with insufficient numbers of women in this study was sought minimized by including women at two centers over a 2.5-year inclusion period. However, a large proportion of our pregnant women with type 2 diabetes had insufficient Danish skills and could for ethical reasons not be included.

A participation in a clinical trial often enhances general awareness of the participant and the caregiver and it is possible that there has been more focus on appropriate insulin treatment in the intervention cohort. On the other hand, healthy eating may reduce hyperglycemia and enable the women to obtain more sufficient insulin treatment without suffering from pronounced hypoglycemia.

An evaluation of the maternal food intake including carbohydrate, fat and protein intake as well as physical activity would have improved the study.

The lifestyle coaches were two midwives with special education and training in the motivational interviewing with focus on healthy eating and had years of experience from the DALI study where using midwifes was documented effective. ${ }^{20}$ The women in both cohorts received dietary guidance by a registered dietitian according to local practice. Whether training of the local dietitian in the motivational interviewing would have given different results remains speculative.
The goals for the gestational weight gain for the women in both cohorts were according to the Copenhagen guidelines that are stricter than the IOM guidelines. However, the weight gain was given as insufficient/ appropriate/excessive according to the IOM guidelines in order to compare the results with other studies.

In conclusion, motivational interviewing to improve adherence to healthy eating in addition to routine care in women with type 2 diabetes tended to reduce fetal overgrowth without major effect on gestational weight gain. Further studies investigating the cost-benefit of enhancing motivation for adherence to treatment goals are needed.

Acknowledgements We kindly thank the midwife at Rigshospitalet, Maria Anna Mikkelsen, and the midwife at Odense University Hospital, Ane Boa, for helping with the inclusion, doing a great job at giving motivational interviewing to the patients as well as help with the data collection. Also, we thank the nurses at the Center for Pregnant Women with Diabetes at Rigshospitalet for the help of recruiting patients for this study. Finally, we thank all the participants for their time and hard work for this study.

Contributors BÁ contributed to the idea, collected and researched the data, wrote the manuscript and contributed to the discussion. MV collected the data, contributed to the discussion and reviewed and edited the manuscript. LR, LLTA, and DMJ contributed to the discussion and reviewed and edited the manuscript. PD and ERM contributed to the idea and discussion and reviewed and edited the manuscript. ERM is the guarantor of this work and as such had full access to all the data in the study and takes responsibility for the integrity of the data and the accuracy of the data analysis.

Funding This study was supported by The Novo Nordisk Foundation.

Disclaimer The sponsor of the study was not involved in the design, conduct, or interpretation of the study.

Competing interests None declared.

Patient consent for publication Not required.

Ethics approval The protocol was approved by the local ethical committee of the capital region of Denmark ( $\mathrm{H}-15009413)$. The study was registered at ClinicalTrials. gov. All patients gave written informed consent as appropriate according to Danish laws. The principles of the Helsinki Declaration were followed.

Provenance and peer review Not commissioned; externally peer reviewed.

Data availability statement Data are available upon reasonable request.

Open access This is an open access article distributed in accordance with the Creative Commons Attribution Non Commercial (CC BY-NC 4.0) license, which permits others to distribute, remix, adapt, build upon this work non-commercially, and license their derivative works on different terms, provided the original work is properly cited, appropriate credit is given, any changes made indicated, and the use is non-commercial. See: http://creativecommons.org/licenses/by-nc/4.0/.

ORCID iD

Björg Ásbjörnsdóttir http://orcid.org/0000-0002-0178-3663

\section{REFERENCES}

1 Metcalfe A, Sabr Y, Hutcheon JA, et al. Trends in obstetric intervention and pregnancy outcomes of Canadian women with diabetes in pregnancy from 2004 to 2015 . J Endocr Soc 2017;1:1540-9.

2 Mayer-Davis EJ, Lawrence JM, Dabelea D, et al. Incidence trends of type 1 and type 2 diabetes among Youths, 2002-2012. N Engl J Med 2017;376:1419-29.

3 Bashir M, Dabbous Z, Baagar K, et al. Type 2 diabetes mellitus in pregnancy: the impact of maternal weight and early glycaemic control on outcomes. Eur J Obstet Gynecol Reprod Biol 2019;233:53-7.

4 Murphy HR, Bell R, Cartwright C, et al. Improved pregnancy outcomes in women with type 1 and type 2 diabetes but substantial clinic-to-clinic variations: a prospective nationwide study. Diabetologia 2017;60:1668-77. 
5 Parellada CB, Ásbjörnsdóttir B, Ringholm L, et al. Fetal growth in relation to gestational weight gain in women with type 2 diabetes: an observational study. Diabet. Med. 2014;31:1681-9.

6 Jolly MC, Sebire NJ, Harris JP, et al. Risk factors for macrosomia and its clinical consequences: a study of 350,311 pregnancies. Eur $J$ Obstet Gynecol Reprod Biol 2003;111:9-14.

7 Rosen H, Shmueli A, Ashwal E, et al. Delivery outcomes of large-forgestational-age newborns stratified by the presence or absence of gestational diabetes mellitus. Int J Gynecol Obstet 2018;141:120-5.

8 Ornoy A. Prenatal origin of obesity and their complications: gestational diabetes, maternal overweight and the paradoxical effects of fetal growth restriction and macrosomia. Reprod Toxicol 2011;32:205-12.

9 Dietz PM, Callaghan WM, Sharma AJ. High pregnancy weight gain and risk of excessive fetal growth. Am J Obstet Gynecol 2009;201:51.e1-51.e6.

$10 \mathrm{Yu}$ CKH, Teoh TG, Robinson S. Obesity in pregnancy. BJOG 2006;113:1117-25.

11 Ladfors L, Shaat N, Wiberg N, et al. Fetal overgrowth in women with type 1 and type 2 diabetes mellitus. PLoS One 2017;12:e0187917.

12 Secher AL, Parellada CB, Ringholm L, et al. Higher gestational weight gain is associated with increasing offspring birth weight independent of maternal glycemic control in women with type 1 diabetes. Diabetes Care 2014;37:2677-84.

13 Harper LM, Shanks AL, Odibo AO, et al. Gestational weight gain in insulin-resistant pregnancies. J Perinatol 2013;33:929-33.

14 Egan AM, Dennedy MC, Al-Ramli W, et al. ATLANTIC-DIP: excessive gestational weight gain and pregnancy outcomes in women with gestational or pregestational diabetes mellitus. J Clin Endocrinol Metab 2014;99:212-9.

15 Yee LM, Cheng YW, Inturrisi M, et al. Effect of gestational weight gain on perinatal outcomes in women with type 2 diabetes mellitus using the 2009 Institute of medicine guidelines. Am J Obstet Gynecol 2011;205:257.e1-257.e6.

16 Muktabhant B, Lawrie TA, Lumbiganon P, et al. Diet or exercise, or both, for preventing excessive weight gain in pregnancy. Cochrane Database Syst Rev 2015;6.

17 Rollnick S, Miller WR. What is motivational interviewing? Behav Cogn Psychother 1995;23:325-34.

18 Hettema J, Steele J, Miller WR. Motivational interviewing. Annu Rev Clin Psychol 2005;1:91-111.

19 Hunt J. Motivational interviewing and people with diabetes. European Diabetes Nursing 2011;8:68-73.

20 Simmons D, Devlieger R, van AA, et al. Effect of physical activity and/or healthy eating on GDM risk: the DALI lifestyle study. J Clin Endocrinol Metab 2017;102:903-13.

21 Roskjær AB, Andersen JR, Ronneby $\mathrm{H}$, et al. Dietary advices on carbohydrate intake for pregnant women with type 1 diabetes. The Journal of Maternal-Fetal \& Neonatal Medicine 2015;28:229-33.

22 Ringholm L, Ásbjörnsdóttir B, Andersen $\mathrm{HU}$, et al. Dietary advice and glycaemic control in women with type 1 diabetes during preconception counselling, pregnancy and breastfeeding.
In: Nutrition and diet in maternal diabetes. First Edition, 2018: 385-400Springer.

23 Rasmussen KM, Yaktine AL. Weight Gain During Pregnancy: Reexamining the Guidelines, 2009. Available: http://www.nap.edu/ catalog.php?record_id=12584 [Accessed 29 April 2012].

24 Durnin JVGA, Womersley J. Body fat assessed from total body density and its estimation from skinfold thickness: measurements on 481 men and women aged from 16 to 72 years. Br J Nutr 1974;32:77-97.

25 Maršál K, Persson P-H, Larsen T, et al. Intrauterine growth curves based on ultrasonically estimated foetal weights. Acta Paediatr 1996;85:843-8

26 The Gestation Network. West Midlands perinatal Institute, Birmingham UK. Available: https://www.gestation.net/growthcharts. htm [Accessed 4 April 2019].

27 Feig DS, Corcoy R, Jensen DM, et al. McIntyre HD: diabetes in pregnancy outcomes: a systematic review and proposed codification of definitions. Diabetes Metab Res Rev 2015.

28 Vinter CA, Jensen DM, Ovesen P, et al. The lip (lifestyle in pregnancy) study: a randomized controlled trial of lifestyle intervention in 360 obese pregnant women. Diabetes Care 2011;34:2502-7.

29 Walsh JM, McGowan CA, Mahony R, et al. Low glycaemic index diet in pregnancy to prevent macrosomia (ROLO study): randomised control trial. BMJ 2012;345:e5605.

30 Dodd JM, Turnbull D, McPhee AJ, et al. Antenatal lifestyle advice for women who are overweight or obese: limit randomised trial. BMJ 2014;348:g1285.

31 Koivusalo SB, Rono K, Klemetti MM, et al. Stach-Lempinen B: gestational diabetes mellitus can be prevented by lifestyle intervention: the Finnish gestational diabetes prevention study (RADIEL): a randomized controlled trial. Diabetes Care 2016;39:24-30.

32 Poston $\mathrm{L}$, Bell $\mathrm{R}$, Croker $\mathrm{H}$, et al. Effect of a behavioural intervention in obese pregnant women (the upbeat study): a multicentre, randomised controlled trial. The Lancet Diabetes \& Endocrinology 2015;3:767-77.

33 Cunningham FG, Williams JW. Williams obstetrics. 112, 2009.

34 van Poppel MNM, Simmons D, Devlieger R, et al. A reduction in sedentary behaviour in obese women during pregnancy reduces neonatal adiposity: the DALI randomised controlled trial. Diabetologia 2019;62:915-25.

35 Renault K, Nørgaard K, Andreasen KR, et al. Physical activity during pregnancy in obese and normal-weight women as assessed by pedometer. Acta Obstet Gynecol Scand 2010;89:956-61.

36 Renault KM, Nørgaard K, Nilas L, et al. The treatment of obese pregnant women (top) study: a randomized controlled trial of the effect of physical activity intervention assessed by pedometer with or without dietary intervention in obese pregnant women. Am J Obstet Gynecol 2014:210:134.e1-134.e9.

37 Abu-Saad K, Fraser D. Maternal nutrition and birth outcomes. Epidemiol Rev 2010;32:5-25. 